\title{
Clima organizacional: um Estudo de Caso com Auditores Técnicos de Controle Externo do Tribunal de Contas do Estado do Amazonas (TCE/AM)
}

Organizational climate: A case study with External Control Technical Auditors of the State of Amazonas Court of Auditors (TCE/AM)

Clima organizacional: Un estudio de caso con Auditores Técnicos de Control Externo del Tribunal de Cuentas del Estado de Amazonas (TCE/AM)

Robson Wagner Rodrigues Monteiro Júnior ${ }^{1}$ robson_wagner321@hotmail.com http://lattes.cnpq.br/8163884073390282 https://orcid.org/0000-0001-5001-8119

Ana Flávia de Morais Morais ${ }^{1}$ anaflavia@ufam.edu.br http://lattes.cnpq.br/2425311272367708 https://orcid.org/0000-0001-5358-3367

Universidade Federal do Amazonas, UFAM, Brasil ${ }^{1}$

Recebido em: 07/09/2019 / Revisão: 01/08/2020 / Aprovado em: 04/11/2020

Editores responsáveis: Prof. Dr. Antônio Giovanni Figliuolo Uchôa e Prof. Dr. Jonas Fernando Petry

Processo de Avaliação: Double Blind Review

DOI: https://10.47357/ufambr.v3i1.6258 


\title{
Resumo
}

Este artigo tem como objetivo analisar a influência do clima organizacional sobre a produtividade dos servidores da Diretoria de Controle Externo de Obras Públicas do Tribunal de Contas do Estado do Amazonas. O clima organizacional é um fator fundamental ao sucesso da organização e pode ser utilizado pela administração como estratégia organizacional para a melhor condução da Gestão de Pessoas. O TCE/AM, por meio do programa "Estoque Zero", espera que os setores realizem uma redução nos estoques de processos e uma maior eficácia nos trabalhos. Nesse contexto, foram definidos como objetivos específicos: Avaliar o clima organizacional da DICOP por meio de 8 variáveis organizacionais; identificar se o clima organizacional da DICOP exerce influência sobre a produtividade, e apresentar melhorias para a gestão do clima organizacional, se necessário. Quanto à Metodologia, a natureza da pesquisa foi definida como aplicada. No que se refere aos objetivos, este foi um estudo do tipo descritivo. Em relação à abordagem, esta foi uma pesquisa quantitativa. No tocante aos procedimentos, realizou-se um estudo de caso único e survey. Para a coleta dos dados foi utilizado um questionário contendo 25 questões fechadas. Acerca dos resultados obtidos, tem-se que $76 \%$ responderam que o clima organizacional exerce influência sobre a produtividade. Tal resultado indica que o clima organizacional da DICOP influencia fortemente a produtividade. Dessa forma, os dirigentes da Corte de Contas do Amazonas devem tornar o clima mais satisfatório para a implementação do programa "Estoque Zero".

Palavras-chave: Clima organizacional. Produtividade. Variáveis organizacionais.

\section{Organizational climate: A case study with External Control Technical Auditors of the State of Amazonas Court of Auditors (TCE/AM)}

\begin{abstract}
This article aims to analyze the influence of the organizational climate on the productivity of the employees of the Directorate for External Control of Public Works of the State of Amazonas Court of Auditors. The organizational climate is a fundamental factor for the success of the organization and can be used by management as an organizational strategy for better management of People Management. TCE/AM, through the "Zero Stock" program, expects the sectors to reduce process stocks and make work more efficient. In this context, specific objectives were defined: To assess the organizational climate of DICOP through 8 organizational variables; identify whether the DICOP organizational climate influences productivity, and present improvements for the management of the organizational climate, if necessary. As for the Methodology, the nature of the research was defined as applied. About the objectives, this was a descriptive study. Regarding the approach, this was a quantitative survey. Regarding the procedures, a single case study and survey was carried out. For data collection, a questionnaire containing 25 closed questions was used. Regarding the results obtained, $76 \%$ answered that the organizational climate influences productivity. This result indicates that DICOP's organizational climate strongly influences productivity. Thus, the directors of the Court of Accounts of Amazonas should make the climate more satisfactory for the implementation of the "Zero Stock" program.
\end{abstract}

Keywords: Climate organization. Productivity. Organizational variables.

UFAMBR, Manaus, v. 3, n. 1, art. 4, pp. 54-78, janeiro-junho, 2021 http://www.periodicos.ufam.edu.br/ufambr 


\section{Clima organizacional: Un estudio de caso con Auditores Técnicos de Control Externo del Tribunal de Cuentas del Estado de Amazonas (TCE/AM)}

\section{Resumén}

Este artículo tiene como objetivo analizar la influencia del clima organizacional en la productividad de los empleados de la Dirección de Control Externo de Obras Públicas del Tribunal de Cuentas del Estado de Amazonas. El clima organizacional es un factor fundamental para el éxito de la organización y puede ser utilizado por la gerencia como una estrategia organizacional para una mejor gestión de la Gestión de Personas. El TCE/AM, mediante del programa "Cero Stock", espera que los sectores reduzcan los stocks de proceso y hagan que el trabajo sea más eficiente. En este contexto, se definieron objetivos específicos: evaluar el clima organizacional de DICOP a través de 8 variables organizacionales; identificar si el clima organizacional de DICOP influye en la productividad y presentar mejoras para gestión del clima organizacional, si es necesario. En cuanto a la Metodología, la naturaleza de la investigación se definió como aplicada. Con respecto a los objetivos, este fue un estudio descriptivo. Con respecto al enfoque, esta fue una encuesta cuantitativa. En cuanto a los procedimientos, se realizó un único estudio de caso y survey. Para la recolección de datos, se utilizó un cuestionario que contenía 25 preguntas cerradas. En cuanto los resultados obtenidos, el $76 \%$ respondió que el clima organizacional influye en la productividad. Este resultado indica que el clima organizacional de DICOP influye fuertemente en la productividad. Por lo tanto, los directores del Tribunal de Cuentas de Amazonas deberían hacer que el clima sea más satisfactorio para la implementación del programa "Cero Stock".

Palabras clave: Clima organizacional. Productividad. Variables organizacionales. 


\section{INTRODUÇÃo}

O conceito de clima organizacional tem evoluído na literatura de uma simples medida para conhecer a forma como as pessoas se sentem no que se refere à organização e seus dirigentes para o conceito de qualidade de vida no trabalho (Maximiano, 2009). Para Santos e Paranhos (2017), o clima organizacional se relaciona à percepção formal ou informal de diversos aspectos como políticas, atitudes, processos e práticas organizacionais que influenciam na eficiência e nos resultados, tal qual como no comportamento dos colaboradores. Isso demonstra que as organizações que buscam um clima favorável acabam possuindo trabalhadores com um potencial de desempenho elevado.

Segundo Lacombe (2012), o clima organizacional expressa a qualidade do ambiente de trabalho na percepção das pessoas que compõem a organização. Sendo fortemente influenciado pela cultura da instituição e da maneira em que os funcionários são tratados. Com isso, o clima se torna algo que não pode ser visto. Porém, pode ser percebido por meio do comportamento dos colaboradores.

Assim, as empresas e órgãos públicos precisam conhecer os sentimentos e pensamentos dos seus empregados ou servidores referentes às variáveis organizacionais que afetam o clima organizacional, tais como: salário, comunicação, trabalho que realizam, supervisão, estabilidade no emprego, benefícios, entre outros. Isso se faz necessário, pois algumas organizações podem apresentar sinais de que o clima organizacional não está satisfatório e, portanto, demonstram baixa produtividade, desperdícios, alta rotatividade, absenteísmo e conflitos no ambiente de trabalho. De acordo com Luz (2003), gerenciar o clima se tornou uma ação estratégica para todas as organizações, de preferência àquelas comprometidas com a gestão pela qualidade.

No que concerne à produtividade no setor público, é notável a busca por medidas de avaliação de desempenho para os funcionários, visando o monitoramento da sua produtividade. Todavia, não é o suficiente para a gestão de pessoas, uma vez que levam em conta somente os efeitos. Logo, evidencia-se a pesquisa de clima organizacional na procura por melhorar os recursos humanos das instituições públicas e privadas (Pública, 2018).

Diante desse cenário, o Tribunal de Contas do Estado do Amazonas (TCE/AM) está implementando um programa de melhoria na produtividade de todos os setores, denominado "Estoque Zero", tendo como objetivo reduzir o estoque de processos. Além disso, o programa visa dar mais credibilidade junto à sociedade, trabalhando de maneira mais rápida e com transparência.

A partir do exposto, o presente artigo buscou responder o seguinte problema: Qual a influência que o clima organizacional exerce sobre a produtividade dos servidores da Diretoria de Controle Externo de Obras Públicas do TCE/AM? Procedendo do problema de pesquisa anteriormente descrito, este artigo tem como objetivo geral analisar a influência do clima organizacional sobre a produtividade dos servidores da Diretoria de Controle Externo de Obras Públicas (DICOP) do Tribunal de Contas do Estado do Amazonas.

Para alcançar o que foi proposto, foram estabelecidos os seguintes objetivos específicos: Avaliar o clima organizacional da DICOP por meio de 8 (oito) variáveis organizacionais; Identificar se o 
Clima organizacional: Um estudo de caso com Auditores Técnicos de Controle Externo do Tribunal de Contas do Estado do Amazonas (TCE/AM)

clima organizacional da DICOP exerce influência sobre a produtividade; e, por fim, apresentar melhorias para gestão do clima organizacional, se necessário.

Este artigo encontra-se dividido em cinco seções: a primeira apresenta a introdução; na segunda seção está o referencial teórico que aborda os conceitos de clima organizacional e sua relação com a produtividade no setor público. A terceira seção refere-se aos procedimentos metodológicos, na qual são apresentados as técnicas e os procedimentos utilizados. A quarta seção demonstra toda a análise dos dados e a quinta seção apresenta a conclusão.

\section{REFERENCIAL TEÓRICO}

Nesta seção serão apresentados conceitos que possuem relação com o objeto estudado.

\subsection{Clima Organizacional}

O clima organizacional é "uma percepção dos membros da organização sobre sua empresa e poderá influir nas suas atitudes" (Nursalam, Elina \& Wahyuni, 2017, p. 1, tradução nossa). É algo intrínseco que influencia as atitudes e o comportamento dos grupos sociais formados dentro das organizações.

Uma organização é feita de pessoas e como tais, estão sujeitas às diversas alterações e influências tanto do ambiente interno, quanto externo, resultando em diversas demonstrações de sentimentos e reação. Quando as emoções vividas pelos empregados e as consequências advindas do ambiente da organização se juntam e influenciam na motivação e o comportamento das pessoas, denominamos de clima organizacional Serviço Brasileiro de Apoio às Micro e Pequenas Empresas [SEBRAE] (2017).

Para Taniguchi e Costa (2010), o clima organizacional tem sido estudado desde o século passado por diversos estudiosos da área de recursos humanos e tem sido um desafio para as organizações, pois é difícil definir e entender as influências que ocorrem na empresa ou órgão. Mas a cada dia, tem se estudado e aprimorado as técnicas de pesquisas de clima organizacional com o intuito de melhorar e criar um clima satisfatório nas organizações, utilizando-o como um fator competitivo.

De acordo com Filho e Ribeiro (2012), os diferentes aspectos dos empregados de uma organização formam o clima organizacional que se instala por toda a organização, idealizando os aspectos da organização, e isso pode ocorrer tanto em empresas públicas, privadas e do terceiro setor. Por isso, é necessário avaliar o clima e utilizá-lo de forma estratégica a favor da organização.

Avaliar o clima organizacional possibilita a organização saber como está o clima no ambiente de trabalho, por meio de um questionário, e assim saber quais as causas do conflito que possam estar ocorrendo no local de trabalho (Luz, 2006).

Segundo Pérez (2017), a organização deve identificar, por meio de um sistema gerencial de informações, as diferentes necessidades e objetivos individuais dos empregados, a fim de ajudar na identificação de atributos que estejam intrinsecamente ligados ao clima organizacional. Pelo

UFAMBR, Manaus, v. 3, n. 1, art. 4, pp. 54-78, janeiro-junho, 2021 http://www.periodicos.ufam.edu.br/ufambr 
Clima organizacional: Um estudo de caso com Auditores Técnicos de Controle Externo do Tribunal de Contas do Estado do Amazonas (TCE/AM)

fato de ser fator chave para a organização, o clima organizacional afeta diretamente o denominado espírito da organização e por isso as dificuldades, os fatores orientados ao comportamento e os estilos de gestão devem ser prioridades na investigação a partir da pesquisa de clima. Lima, Leuch e Buss (2017) endossam que:

A maneira mais adequada para medir o nível de satisfação e o clima da empresa é a pesquisa de clima organizacional. É por meio dela que o colaborador demonstra o seu grau de satisfação com relação ao seu trabalho, a sua função, sua remuneração etc. (Lima, Leuch \& Buss, 2017, p.13).

Diferentemente da cultura organizacional que se faz presente desde a criação do negócio, o clima organizacional afeta vários fatores na organização de forma dinâmica. As mudanças no ambiente interno e externo, podem causar um impacto significativo na organização e são os motivos que fazem com que o clima esteja em constante mudança na empresa (Oliveira, Carvalho \& Rosa, 2012).

A pesquisa de clima organizacional é uma ferramenta estratégica de gestão porque mede diversos fatores organizacionais, entre eles a satisfação, dando à organização o diagnóstico necessário para a realização de mudanças e alternativas para criar formas de motivar os empregados. Com isso, se tem a grande importância da pesquisa de clima que contribui para o melhor desempenho da empresa (Machado \& Goulart, 2014).

Dentre os fatores que influenciam o clima da organização está um dos mais relevantes que é a motivação, tendo como conceito um motivo, uma necessidade do indivíduo de se satisfazer, o que estimula a pessoa a realizar uma ação (Ferreira et al, 2006).

A motivação pode ser considerada como o aspecto mais difícil de trabalhar dentro da organização, tendo em vista que para cada indivíduo a motivação é algo diferente, já que cada um tem suas necessidades sendo essas diferentes umas das outras, tornando a missão da organização de unir as pessoas a seu propósito cada vez mais desafiadora (Staudt \& Reggiori, 2016).

Para medir o clima organizacional é preciso definir quais variáveis organizacionais serão pesquisadas. Nessa etapa, a empresa poderá escolher aquelas que julgar mais relevantes e algumas variáveis especificas de acordo com a sua realidade. A partir disso, o estudo identifica não só o impacto sobre os colaboradores, mas também a percepção e reação a cada variável (Luz, 2003). Algumas variáveis que podem ser escolhidas nessa etapa:

O trabalho realizado pelos funcionários; salário; benefícios; integração entre os departamentos da empresa; supervisão, liderança, estilo gerencial e gestão; comunicação; treinamento, desenvolvimento, carreira, progresso e realização profissional; possibilidades de progresso profissional; relacionamento interpessoal; estabilidade no emprego; processo decisório; condições físicas de trabalho; relacionamento da empresa com os sindicatos e funcionários (Luz, 2003, pp. 42-46).

\subsection{Clima Organizacional e a Produtividade no Setor Público}

UFAMBR, Manaus, v. 3, n. 1, art. 4, pp. 54-78, janeiro-junho, 2021 http://www.periodicos.ufam.edu.br/ufambr 
Clima organizacional: Um estudo de caso com Auditores Técnicos de Controle Externo do Tribunal de Contas do Estado do Amazonas (TCE/AM)

Para compreender essa relação entre clima e sua influência na produtividade de algum indivíduo ou grupo de trabalho é importante saber o entendimento de produtividade e eficiência no setor público.

Aumentar a produtividade no trabalho, encontrar maneiras de gerar resultados satisfatórios e atingir desafios estabelecidos são temas do cotidiano de muitos dirigentes e colaboradores. No setor público, a produtividade está intimamente relacionada à eficiência e principalmente ao tempo, visto que a ideia de que quanto menos tempo é desperdiçado, mais produtivo será o servidor nunca foi tão verdadeira (Nittis, 2018).

Teóricos clássicos como Adam Smith, Taylor e Charles Babbage, procuravam maneiras de melhorar a produção; desenvolveram procedimentos administrativos para melhorar a eficiência no trabalho e, por sua vez, contribuíram para os resultados no setor público (Maximiano, 2015)

Ao analisar a eficiência no serviço público, não se deve direcionar apenas para a otimização dos recursos, mas ao alcance de resultados satisfatórios para a administração pública. Nesse sentido, a eficiência passou a ser fator relevante durante a Reforma Gerencial na década de noventa no Brasil. Segundo Bugarin e Meneguin (2016), os administradores públicos passaram a se inspirar pela Nova Gestão Pública, na procura pela melhoria da eficiência no serviço público.

O clima organizacional tem sido considerado um fato relevante para a sucesso da organização, especialmente para a produtividade que, por sua vez, está relacionado a motivação e satisfação dos funcionários (Rocha, Ceretta \& Lima, 2014). Dessa forma, pesquisas tem indicado que o clima organizacional afeta vários fatores em uma instituição inclusive o desempenho dos colaboradores (Araújo et al, 2017).

No setor público, segundo Saraiva (2002), as características das organizações públicas afetam os comportamentos dos indivíduos em que se observa uma relutância as mudanças, não preocupação salarial e desinteresse nos resultados. Ademais, a gestão de pessoas é afetada pelos interesses políticos e pela burocracia. Essas organizações públicas se diferenciam na estrutura, desempenho das pessoas, processos e tecnologia (Carbone, 2000).

É necessário levar em consideração as reformas administrativas que têm ocorrido no setor público, pois tem sido alterado o comportamento dos servidores e das instituições públicas.

Estratégias governamentais que influenciam na mudança da cultura organizacional do serviço público contribuem para modificar o comportamento dos servidores dando-lhes alguma insegurança e desconfiança quanto ao seu futuro no trabalho. O resultado é que há implicações para os gestores e para a área de Gestão de Pessoas, que tem a necessidade de agir fortemente com relação à melhoria do Clima Organizacional (Oliveira \& Medeiros, 2011, pp. 124-125).

É fato que há poucas semelhanças na gestão pública quando comparada a uma empresa privada, já que cada uma possui características básicas e próprias. Assim, sugere-se a gestão social como forma de "tentar substituir a gestão tecno burocrática, monológica, por meio de um gerenciamento mais participativo, ideológico, no qual o processo decisório passa a ser exercido por meio de diferentes sujeitos sociais" (Habermas, 1989 como citado em Tenório, 1998, p.16). Isso é de 
Clima organizacional: Um estudo de caso com Auditores Técnicos de Controle Externo do Tribunal de Contas do Estado do Amazonas (TCE/AM)

fundamental importância, visto que quando o colaborador participa do processo decisório se sente engajado, influenciando diretamente na produtividade.

À vista disso, o gestor enfrentará resistência ao aplicar mudanças drásticas na cultura organizacional uma vez que se encontra de maneira enraizada no setor público. Porém, as pequenas mudanças podem aos poucos motivar os servidores a alcançar o sucesso organizacional.

Nesse cenário, os responsáveis pelos processos produtivos devem fazer que esses processos sejam rápidos, utilizem menos recursos e atendam com melhor qualidade.

Entre os fatores envolvidos no processo produtivo estão os seres humanos que assumem maior importância, pois são os indivíduos que serão capazes de aumentar ou diminuir a produtividade, de melhorar ou piorar a qualidade de um serviço e, ainda, gerar maior ou menor lucro para as organizações (Affonso \& Rocha, 2010, p.1).

Segundo o Ministério da Fazenda (2016), 40\% das receitas da União em 2015 foram destinadas à folha de pagamento de servidores federais, e nos Estados da federação esse percentual subiu para $60 \%$ das receitas arrecadadas. Com isso, nota-se um gasto significativo com despesa de pessoal e mesmo assim o setor público apresenta índices de qualidade e produtividade que podem ser melhorados.

Conforme Mallet (2009), os inimigos de um clima organizacional voltado para a produtividade são os problemas de relacionamento entre gestores e colaboradores, ausência de comunicação eficiente, atitudes negativas das pessoas e falta de estabilidade emocional.

Em virtude do que foi exposto no referencial teórico que explica o entendimento do clima organizacional e sua relação com a produtividade no setor público, iniciou-se o desenvolvimento dos procedimentos metodológicos para alcançar o objetivo geral dessa pesquisa.

\section{PROCEDIMENTO METODOLÓGICO}

A presente pesquisa teve como objetivo geral analisar o clima organizacional e a influência sobre a produtividade dos servidores da Diretoria de Controle Externo de Obras Públicas do Tribunal de Contas do Estado do Amazonas.

A natureza do estudo foi definida como aplicada, já que consiste em geração de conhecimento para resolver problemas específicos, buscando sempre determinada situação particular, podendo ser denominada também como estabelecimentos de planos, pois visa apresentar soluções para certas questões organizacionais (Nascimento \& Souza, 2015).

A pesquisa então se classifica, segundo o objetivo geral, como uma pesquisa descritiva. Segundo Diehl e Tatim (2004), a pesquisa descritiva tem a finalidade de estudar uma população ou amostra correlacionando variáveis a fenômenos que ocorrem nesse grupo, por meio da utilização de técnicas de coleta de dados como entrevistas ou questionários.

UFAMBR, Manaus, v. 3, n. 1, art. 4, pp. 54-78, janeiro-junho, 2021 http://www.periodicos.ufam.edu.br/ufambr 
Clima organizacional: Um estudo de caso com Auditores Técnicos de Controle Externo do Tribunal de Contas do Estado do Amazonas (TCE/AM)

Quanto à abordagem esta foi uma pesquisa quantitativa, visto que confia na medição numérica e no uso da estatística a fim de ter de forma exata os padrões de comportamento dos colaboradores (Sampieri et al, 2006).

No que se refere aos procedimentos, a pesquisa caracterizou-se como estudo de caso único, uma vez que apura casos de grupos ou isolados, com objetivo de entender os fenômenos sociais. Sua aplicação em campo busca analisar o problema e sugerir soluções (Michel, 2015). De acordo com Ludke e André (2013, p.20) "o estudo de caso, é o estudo de um caso, seja ele simples ou complexo. O caso pode ser similar a outros, mas é ao mesmo tempo distinto, pois tem um interesse próprio, singular".

Utilizou-se ainda o procedimento survey, o qual se caracteriza em procurar informações diretamente com os indivíduos de interesse sobre dados que se deseja saber. Essa técnica obtém dados de um determinado público-alvo com um questionário de instrumento de pesquisa e nele os respondentes não se identificam. Portanto, os dados são sigilosos (Filho \& Arruda, 2013).

O questionário foi elaborado com 25 (vinte e cinco) questões fechadas e foi enviado aos participantes por meio de um link on-line disponibilizado na plataforma Google Forms. A técnica de obtenção de dados por meio de questionário tem por definição uma série de perguntas elaboradas com um determinado fim, entregue a uma população seguindo uma ordem lógica para ser respondido sem a presença do elaborador da pesquisa (Oliveira et al., 2016). O planejamento do questionário que foi usado na pesquisa está na tabela abaixo:

Tabela 1

Planejamento para o questionário utilizado na pesquisa

\begin{tabular}{lll}
\hline Tema das perguntas & $\begin{array}{l}\text { Quantidade } \\
\text { Perguntas }\end{array}$ & de \\
\hline $\begin{array}{l}\text { Questões sobre o perfil dos entrevistados. } \\
\text { Questões voltadas para as variáveis organizacionais. }\end{array}$ & 3 \\
$\begin{array}{l}\text { Questões voltadas para a influência do clima organizacional sobre a } \\
\text { produtividade. }\end{array}$ & 20 \\
\hline
\end{tabular}

* Organizado pelos autores.

Após a coleta dos dados foi realizada a análise. Segundo Gil (2008, p.156), "a análise tem como objetivo organizar e sumariar os dados de forma tal qual que possibilitem o fornecimento de respostas ao problema proposto para a investigação".

No momento da realização desse estudo, a DICOP conta com 32 (trinta e dois) Auditores Técnicos de Controle Externo. A amostra da pesquisa abrangeu 25 respondentes, ou seja, aproximadamente $78,13 \%$ da população, havendo, portanto, a abstenção de $21,87 \%$.

Para realizar a pesquisa sobre o clima organizacional no setor público foi adaptado o modelo de Luz (2003; p. 42-46), utilizando-se no instrumento de coleta 8 (oito) variáveis organizacionais descritas a seguir:

UFAMBR, Manaus, v. 3, n. 1, art. 4, pp. 54-78, janeiro-junho, 2021 http://www.periodicos.ufam.edu.br/ufambr 
Clima organizacional: Um estudo de caso com Auditores Técnicos de Controle Externo do Tribunal de Contas do Estado do Amazonas (TCE/AM)

a) O Trabalho Realizado pelos Funcionários: avalia a adaptação dos funcionários com os trabalhos realizados; volume do trabalho realizado; o horário de trabalho; se é justa a distribuição dos trabalhos entre os funcionários; se o quadro de pessoal em cada setor é suficiente para realizar os trabalhos; se o trabalho é considerado relevante e desafiador; e o equilíbrio entre o trabalho e a vida pessoal.

b) Salário: Analisa a percepção deles quanto à compatibilidade dos salários da empresa com os praticados no mercado; o equilíbrio existente na empresa entre os salários dos cargos de mesma importância; a possibilidade de obtenção de aumentos salariais; a possibilidade de viver dignamente com o salário; o impacto na atração de talentos e na satisfação e fixação dos funcionários; a clareza quantos aos critérios do plano de cargos e salários da empresa.

c) Liderança/Supervisão: revela a satisfação dos funcionários com os seus gestores; a qualidade da supervisão exercida; a capacidade técnica, humana e administrativa dos gestores, o grau de feedback dado por eles à equipe; o tratamento justo dado à equipe.

d) Comunicação: avalia o grau de satisfação com o processo de divulgação dos fatos relevantes da empresa; aponta a satisfação quanto à forma e os canais de comunicação utilizados pela empresa.

e) Treinamento: avalia as oportunidades que os trabalhadores têm de se qualificar, de se atualizar, de se desenvolver profissionalmente.

f) Condições Físicas de Trabalho: verifica a qualidade e o conforto das condições físicas, das instalações, dos recursos colocados à disposição dos funcionários para a realização dos seus trabalhos: posto de trabalho, vestiários, horários de trabalho, local de trabalho, recursos disponíveis para o trabalho.

g) Reconhecimento: avalia o quanto a empresa adota mecanismos de valorização e reconhecimento para seus funcionários.

h) Envolvimento/Comprometimento: avalia o quanto os funcionários se sentem envolvidos e comprometidos com os objetivos e com os resultados da empresa, assim como o quanto essa adesão é voluntária ou compulsória.

\section{RESULTADOS E DISCUSSÃO}

Nesta seção serão apresentados os dados coletados a partir do questionário aplicado. Os resultados foram compilados em gráficos e discutidos conforme a literatura consultada. Em relação a definição dos parâmetros para as perguntas do questionário, foram considerados satisfeitos os servidores que optaram pelas respostas "sempre" ou "quase sempre". As respostas "raramente" e "nunca" foram consideradas manifestações de insatisfação. Além disso, é importante destacar que foram inseridas perguntas com respostas "sim" e "não".

\subsection{Análise do Campo Dados Pessoais}

De acordo com os dados obtidos na pesquisa, observou-se que $72 \%$ (setenta e dois por cento) dos respondentes trabalham no TCE/AM há mais de 5 a 10 anos, e os que possuem um tempo menor de trabalho entre 3 a 5 anos são $24 \%$ (vinte e quatro por cento).

No que se refere ao item "Idade", 48\% (quarenta e oito por cento) dos Auditores está na faixa etária entre 30 e 40 anos. O universo mais jovem, representado por 32\% (trinta e dois por cento), está entre 25 a 30 anos; e apenas $20 \%$ (vinte por cento) tem entre 40 e 50 anos. Tal análise aponta haver necessidade de novos membros uma vez que o Tribunal de Contas do Estado do Amazonas no ano

UFAMBR, Manaus, v. 3, n. 1, art. 4, pp. 54-78, janeiro-junho, 2021 http://www.periodicos.ufam.edu.br/ufambr 
Clima organizacional: Um estudo de caso com Auditores Técnicos de Controle Externo do Tribunal de Contas do Estado do Amazonas (TCE/AM)

de 2020 apresentará muitos aposentados e por isso deve-se buscar uma renovação no quadro de servidores.

Verificou-se ainda que $100 \%$ (cem por cento) dos pesquisados são do sexo masculino. A pesquisa não obteve respostas do sexo feminino. $O$ setor privado possui mais facilidade em contratar profissionais com perfis diferentes, levando em consideração fatores sociais, de gênero, culturais, com necessidades especiais e etnia. Já o setor público fica limitado aos aprovados em concursos e cargos comissionados. Entretanto, para uma organização é fundamental ter em seu quadro de funcionários um equilíbrio entre os sexos masculino e feminino.

\subsection{Análise do Campo Variáveis Organizacionais}

A primeira variável analisada nesta pesquisa de clima organizacional foi "Condições de Trabalho" (Tabela 2). Essa variável verifica a qualidade e o conforto à disposição dos funcionários para a realização dos seus trabalhos (Luz, 2003).

Tabela 2

Variável Condições de Trabalho

\begin{tabular}{lcc}
\hline 1. As condições de trabalho no TCE/AM são satisfatórias (ruídos, & \multirow{2}{*}{ Respondentes } & $\%$ \\
temperatura, higiene, mobiliário etc.)? & 10 & $40 \%$ \\
\hline Sim & 15 & $60 \%$ \\
Não & 0 & $0 \%$ \\
Mais ou menos & Respondentes & $\%$ \\
\hline 2. Os recursos tecnológicos colocados à disposição dos & 14 & $56 \%$ \\
funcionários para a realização do seu trabalho são satisfatórios? & 10 & $40 \%$ \\
\hline Sim & 1 & $4 \%$ \\
Não & & $\%$ \\
\hline
\end{tabular}

Fonte: Dados da pesquisa, 2019.

Conforme a primeira questão analisada, $60 \%$ dos respondentes estão insatisfeitos com as condições de trabalho e apenas $40 \%$ se encontram satisfeitos. Todavia, esta variável pode ter sido afetada em virtude do Tribunal de Contas do Estado do Amazonas estar, quando da realização desse estudo, em reforma na sua estrutura interna. Portanto, os servidores podem ter sido influenciados por sons de maquinário pesado, temperatura e higiene alteradas entre outros incômodos. Apesar disso, é fundamental o conforto das condições físicas e das instalações para realização dos trabalhos.

No segundo questionamento, $56 \%$ dos servidores afirmam que os recursos tecnológicos colocados à disposição para a realização dos trabalhos são satisfatórios. Porém, é preciso levar em consideração que $40 \%$ estão insatisfeitos com a tecnologia utilizada na realização dos trabalhos. É importante que os gestores do Tribunal de Contas Estado do Amazonas identifiquem quais desses recursos geram insatisfação, tais como: internet, sistemas, intranet, pasta compartilhada, computadores e solucionem para que a satisfação na realização dos trabalhos seja ainda maior.

UFAMBR, Manaus, v. 3, n. 1, art. 4, pp. 54-78, janeiro-junho, 2021 http://www.periodicos.ufam.edu.br/ufambr 
Clima organizacional: Um estudo de caso com Auditores Técnicos de Controle Externo do Tribunal de Contas do Estado do Amazonas (TCE/AM)

Segundo Bortolozo e Santana (2011), os gestores devem se preocupar com condições de trabalho que são oferecidas aos colaboradores, objetivando contribuir para a satisfação e produção de cada funcionário.

A segunda variável analisada foi "Comprometimento" (Tabela 3) que, segundo Luz (2003), avalia o envolvimento e comprometimento dos colaboradores com os resultados e metas da organização

Tabela 3

Variável Comprometimento

\begin{tabular}{lcc}
\hline 3. Você gostaria de trabalhar em outro departamento do & Respondentes & $\%$ \\
TCE/AM? & 5 & $20 \%$ \\
\hline Sim & 20 & $80 \%$ \\
Não & Respondentes & $\%$ \\
\hline 4. Você se sente envolvido e comprometido com os objetivos & 12 & $48 \%$ \\
organizacionais? & 13 & $52 \%$ \\
\hline Sim & & \\
Não. & & \\
\hline
\end{tabular}

Fonte: Dados da pesquisa, 2019.

Como demonstrado no terceiro questionamento, o resultado dessa variável apresentou um alto nível de comprometimento com a Diretoria de Controle Externo de Obras Públicas, visto que 80\% responderam que não gostariam de trabalhar em outro departamento do TCE/AM, sendo que somente $20 \%$ responderam sim à pergunta. O comprometimento com o setor de trabalho indica que a equipe está unificada e não há descontentamento com os integrantes do setor.

Em seguida, percebe-se que os Auditores Técnicos de Controle Externo não estão comprometidos com os objetivos organizacionais haja vista que $52 \%$ responderam não e $48 \%$ se sentem envolvidos com os objetivos. É preciso verificar se há falha na comunicação dos objetivos do órgão aos seus servidores.

De acordo com Gonçalves (2016), o comprometimento está relacionado à disposição do colaborador em cumprir aquilo que é designado como tarefa dentro da instituição. Por isso, essa variável se torna importante devido a influência que possui sobre o clima organizacional.

O comprometimento está ligado aos laços que o indivíduo possui com seu trabalho, ou seja, criase um envolvimento com diversos aspectos do trabalho, principalmente com a empresa empregadora (Spector, 2010).

Dessa forma, para que o TCE/AM alcance a redução do estoque de processos é necessário que todos os seus servidores estejam comprometidos e envolvidos com as metas e programas propostos pelos seus dirigentes.

Em relação ao item "O Trabalho Realizado pelos Funcionários” (Tabela 4), avalia-se o volume de trabalho; se existe o trabalho em equipe; as decisões que afetam trabalho e a percepção de quantidade e qualidade (Luz, 2003).

Tabela 4

UFAMBR, Manaus, v. 3, n. 1, art. 4, pp. 54-78, janeiro-junho, 2021 http://www.periodicos.ufam.edu.br/ufambr 
Clima organizacional: Um estudo de caso com Auditores Técnicos de Controle Externo do Tribunal de Contas do Estado do Amazonas (TCE/AM)

Variável Trabalho Realizado pelos Funcionários

\begin{tabular}{|c|c|c|}
\hline $\begin{array}{l}\text { 5. A qualidade do trabalho é considerada mais importante do que } \\
\text { a sua quantidade? }\end{array}$ & Respondentes & $\%$ \\
\hline Sempre & 6 & $24 \%$ \\
\hline Quase sempre & 9 & $36 \%$ \\
\hline Raramente & 7 & $28 \%$ \\
\hline Nunca & 1 & $4 \%$ \\
\hline Não tenho opinião & 2 & $8 \%$ \\
\hline $\begin{array}{l}\text { 6. Você se sente adequadamente informado sobre as decisões que } \\
\text { afetam o seu trabalho? }\end{array}$ & Respondentes & $\%$ \\
\hline Sempre & 3 & $12 \%$ \\
\hline Quase sempre & 10 & $40 \%$ \\
\hline Raramente & 10 & $40 \%$ \\
\hline Nunca & 0 & $0 \%$ \\
\hline Não tenho opinião. & 2 & $8 \%$ \\
\hline 7. O seu superior imediato incentiva o trabalho em equipe? & Respondentes & $\%$ \\
\hline Sim & 7 & $28 \%$ \\
\hline Não & 8 & $32 \%$ \\
\hline Não tenho opinião & 10 & $40 \%$ \\
\hline $\begin{array}{l}\text { 8. Você se sente satisfeito em relação ao volume de trabalho que } \\
\text { realiza? }\end{array}$ & Respondentes & $\%$ \\
\hline Sim & 7 & $28 \%$ \\
\hline Não & 17 & $68 \%$ \\
\hline Não tenho opinião. & 1 & $4 \%$ \\
\hline
\end{tabular}

Fonte: Dados da pesquisa, 2019.

A quinta pergunta revelou um resultado em que $60 \%$ (sessenta por cento) afirmam que a qualidade é considerada mais importante que sua quantidade; e $32 \%$ (trinta e dois por cento) dos respondentes acreditam que no seu ambiente de trabalho a quantidade é mais importante. Apenas $8 \%$ (oito por cento) não tem uma opinião em relação ao questionamento. É interessante que os respondestes entendem que a qualidade no trabalho realizado é mais importante, uma vez que para realizar um bom trabalho vai além de cumprir metas diárias. Os dirigentes do TCE/AM devem definir os parâmetros de qualidade, quantidade e tempo esperado para execução e cumprimentos das metas. Além disso, é necessário que se divulgue os indicadores aos colaboradores a fim de que tenham conhecimento do será esperado nos resultados.

A sexta questão demonstra que 52\% (cinquenta e dois por cento) se sentem satisfeitos em relação às decisões que afetam diretamente o seu trabalho. No entanto, os insatisfeitos são relativamente grandes somando $40 \%$ (quarenta por cento); e apenas $8 \%$ (oito por cento) marcaram a opção não ter opinião ao questionamento. A comunicação interna é responsável pela consciência coletiva da organização e ações dos colaboradores que, por sua vez, leva as decisões baseadas nas estratégias organizacionais. Nesse sentido, Medeiros (2006) afirma que a comunicação proporciona melhorias nos resultados almejados por uma instituição, sendo que no caso de órgãos públicos, auxilia tanto na prestação dos serviços à sociedade, quanto no cumprimento das metas organizacionais.

Na sétima pergunta, por uma pequena diferença é possível perceber que o trabalho em equipe não é incentivado diretamente pelo superior imediato, já que 32\% (trinta e dois por cento) escolheram a alternativa "não". Já $28 \%$ (vinte e oito por cento) acreditam que o trabalho em equipe é incentivado no setor; e $40 \%$ (quarenta por cento) não possuem opinião sobre o tema. Sabe-se que UFAMBR, Manaus, v. 3, n. 1, art. 4, pp. 54-78, janeiro-junho, 2021 http://www.periodicos.ufam.edu.br/ufambr 
Clima organizacional: Um estudo de caso com Auditores Técnicos de Controle Externo do Tribunal de Contas do Estado do Amazonas (TCE/AM)

o trabalho em equipe tem um papel importante no resultado. Para potencializar isso, é necessário formar uma equipe unida, que exista o diálogo com respeito; incentivar projetos, por exemplo, treinamentos corporativos em que aproximem todos e façam que se sintam reconhecidos. O líder deve estimular a proatividade, pois ajudará os colaboradores a encontrar soluções para problemas que aparentemente possam parecer difíceis, sem esquecer o reconhecimento que proporciona motivação aos funcionários (Mendonça, 2018).

Em seguida, a insatisfação prevaleceu na pergunta oitava em que $68 \%$ não se sentem satisfeitos com relação ao grande volume de trabalho na Diretoria de Controle Externo de Obras Públicas. Por outro lado, $28 \%$ (vinte e oito por cento) encontram-se satisfeitos e $4 \%$ (quatro por cento) dizem não ter opinião. O programa "Estoque zero" visa diminuir o estoque de processos da Corte e consequentemente aumentar a produtividade dos servidores. Com isso, o aumento do volume de trabalho é inevitável. Porém, não se pode negligenciar a saúde e bem-estar, uma vez que o estresse, falta de sono e ansiedade são consequências do excesso de trabalho (Santana, 2018).

A "Remuneração" (Tabela 5) também foi umas das variáveis analisadas, visto que é uma das principais variáveis a serem pesquisadas, em função do grau de satisfação dos empregados (Luz, 2003).

Tabela 5

Variável Remuneração

\begin{tabular}{lcc}
\hline 9. Sua remuneração é adequada ao trabalho que você faz? & Respondentes & \% \\
\hline Sim & 5 & $20 \%$ \\
Não & 19 & $76 \%$ \\
Mais ou menos. & 1 & $4 \%$ \\
\hline 10. O seu salário satisfaz às suas necessidades básicas de vida? & Respondentes & $\mathbf{\%}$ \\
\hline Sim & 19 & $76 \%$ \\
Não & 3 & $12 \%$ \\
Mais ou menos & 3 & $12 \%$ \\
\hline
\end{tabular}

Fonte: Dados da pesquisa, 2019.

Os resultados do questionamento nono demonstram que $76 \%$ (setenta e seis por cento) estão insatisfeitos com a atual remuneração praticada pelo TCE/AM, e somente $24 \%$ (vinte e quatro por cento) consideram-na adequadas ao trabalho que realizam. É interessante saber que um sistema de remuneração bom contribui para a eficácia organizacional, e se torna uma vantagem competitiva para a organização. $\mathrm{O}$ sistema de remuneração nunca deve ser utilizado apenas para diminuir insatisfações, mas sim para motivar os servidores a exercerem suas funções de uma melhor forma possível (Beuren, Kaveski \& Rigo, 2014).

Na décima questão, percebe-se que para $88 \%$ (oitenta e oito por cento) dos pesquisados, o salário satisfaz às necessidades básicas; e somente $12 \%$ (doze por cento) afirmam não conseguirem satisfazer as necessidades básicas de suas vidas. Como demonstrado na questão nona, a maioria dos pesquisados encontram-se insatisfeitos com a atual remuneração, mas com os dados da décima pergunta, pode-se afirmar que pelo menos os salários têm sido suficientes para as necessidades básicas.

UFAMBR, Manaus, v. 3, n. 1, art. 4, pp. 54-78, janeiro-junho, 2021 http://www.periodicos.ufam.edu.br/ufambr 
Clima organizacional: Um estudo de caso com Auditores Técnicos de Controle Externo do Tribunal de Contas do Estado do Amazonas (TCE/AM)

Em relação à variável "Liderança" (Tabela 6), revela-se a satisfação dos funcionários com seus respectivos gestores; qualidade da supervisão exercida e capacidade administrativa e humana. O líder desempenha um papel importante sobre o clima organizacional, já que seu estilo de gestão pode influenciar positivamente ou negativamente o clima no local de trabalho (Luz, 2003).

Tabela 6

Variável Liderança

\begin{tabular}{lcc}
\hline 11. O seu chefe exerce pressão sobre seu ritmo de trabalho? & Respondentes & \% \\
\hline Sim & 6 & $24 \%$ \\
Não & 18 & $72 \%$ \\
Não tenho opinião. & 1 & $4 \%$ \\
\hline 12. Você considera que seu trabalho é avaliado de forma justa & Respondentes & $\%$ \\
pelos seus superiores? & 5 & $20 \%$ \\
\hline Sempre & 14 & $56 \%$ \\
Quase sempre & 4 & $16 \%$ \\
Raramente & 0 & $0 \%$ \\
Nunca & 2 & $8 \%$ \\
Não tenho opinião & Respondentes & $\%$ \\
\hline 13. Você confia nas decisões tomadas pelo seu superior imediato? & 7 & $28 \%$ \\
Sempre & 12 & $48 \%$ \\
Quase sempre & 4 & $16 \%$ \\
Raramente & 0 & $0 \%$ \\
Nunca & 2 & $8 \%$ \\
Não tenho opinião & & $\%$ \\
\hline
\end{tabular}

Fonte: Dados da pesquisa, 2019.

A partir das respostas apresentadas pelos servidores, percebe-se que para a maioria dos pesquisados, isto é, $72 \%$ (setenta e dois por cento), o chefe não exerce pressão sobre seu ritmo de trabalho; e apenas $24 \%$ (vinte e quatro por cento) disseram haver alguma pressão a respeito do ritmo de trabalho. Logo, $4 \%$ (quatro por cento) não expressaram opinião. A maioria afirma não existir pressão sobre o ritmo de trabalho. Isso de certa forma é bom, pois o excesso atrapalha a performance no trabalho e a vida pessoal do colaborador. Entretanto, é preciso lembrar que a pressão do chefe sempre estará presente na vida profissional. Com isso, saber lidar e procurar encará-la como mais uma fonte de motivação ajudará no crescimento profissional. Dessa forma, se o funcionário deixar de lado o fator negativo poderá vê-la como aliada (Lacava, 2018).

Conforme demonstrado na décima segunda pergunta, o resultado aponta um resultado satisfatório, já que $76 \%$ (setenta e seis por cento) consideram que seus trabalhos são avaliados de maneira justa pelo seu superior; $16 \%$ (dezesseis por cento) acreditam que não são avaliados de forma justa; e 8\% (oito por cento) optaram por não expressar uma opinião. É fundamental que os trabalhos realizados sejam avaliados de forma justa, já que os desempenhos dos funcionários representam a produtividade do setor e no contexto mais amplo, o da organização. Segundo Araújo (2017), ao avaliar a produtividade dos funcionários a instituição buscar fazer um diagnóstico do desempenho que, por sua vez, demonstrará a imagem da equipe de trabalho. Ademais, o autor acrescenta que deverá ser feito um planejamento na escolha do método e análise. Por exemplo, existem métodos tradicionais como o método de escalas gráficas que buscam uma análise matemática do desempenho; ou métodos modernos como a avaliação participativa por objetivos, em que os colaboradores participam, juntamente com os gestores na escolha dos objetivos a serem atingidos.

UFAMBR, Manaus, v. 3, n. 1, art. 4, pp. 54-78, janeiro-junho, 2021 http://www.periodicos.ufam.edu.br/ufambr 
Clima organizacional: Um estudo de caso com Auditores Técnicos de Controle Externo do Tribunal de Contas do Estado do Amazonas (TCE/AM)

Os dados obtidos demonstram a confiança nas decisões tomadas pelo superior imediato. $76 \%$ (setenta e seis por cento) dos servidores pesquisados afirmam confiar nas decisões; 16\% (dezesseis por cento) não confiam; e somente $8 \%$ não expressaram opinião sobre o tema. Na administração pública, "a liderança exerce um papel fundamental, tendo em vista que sua atuação reflete na satisfação, na geração de ideias e reflexão da equipe que, por sua vez, promove a inovação" (Dias \& Borges, 2015).

A variável seguinte "Comunicação" (Tabela 7), avalia-se o processo de divulgação das informações relevantes e a comunicação entre o chefe e colaboradores.

Tabela 7

Variável Comunicação

\begin{tabular}{lcc}
\hline 14. Seu superior imediato é receptivo às sugestões de mudança? & Respondentes & \% \\
\hline Sempre & 12 & $48 \%$ \\
Quase sempre & 7 & $28 \%$ \\
Raramente & 4 & $16 \%$ \\
Nunca & 0 & $0 \%$ \\
Não tenho opinião & 2 & $8 \%$ \\
\hline 15. Você tem uma ideia clara sobre o resultado que o seu & Respondentes & $\%$ \\
superior imediato espera do seu trabalho? & 9 & $36 \%$ \\
\hline Sempre & 11 & $44 \%$ \\
Quase sempre & 1 & $4 \%$ \\
Raramente & 3 & $12 \%$ \\
Nunca & 1 & $4 \%$ \\
Não tenho opinião. & Respondentes \\
\hline 16. Onde você encontra as informações que deseja saber sobre o & 16 & $\%$ \\
TCE/AM? & 8 & $64 \%$ \\
\hline Intranet & 1 & $32 \%$ \\
Colega de trabalho & $4 \%$ \\
Superior imediato & & $4 \%$ \\
\hline
\end{tabular}

Nota: Dados da pesquisa, 2019.

Quanto aos resultados da décima quarta pergunta, notou-se que 76\% (setenta e seis por cento) responderam que consideram o gestor receptivo a opinião dos seus colaboradores; $16 \%$ (dezesseis por cento) afirmam que raramente; e $8 \%$ (oito por cento) não expressaram opinião. Esse questionamento trouxe resultados satisfatórios, uma vez que aponta uma boa relação com o chefe. É importante lembrar que os colaboradores são fontes de ideias que podem ajudar a melhorar o seu setor de trabalho.

Quando no ambiente de trabalho os funcionários podem propor melhorias, sugestões e opiniões, isso é fator de motivação, já que começam a ter mais reconhecimento, papel de decisão e autonomia. Afinal, estão sendo consultados e fazendo partes das conquistas futuras (Belluno, 2020).

Os dados da décima quinta questão são satisfatórios, pois se verificou que $80 \%$ (oitenta por cento) respondeu haver um conhecimento do resultado esperado; uma pequena parcela de 16\% (dezesseis por cento) não tem uma ideia clara; e 4\% (quatro por cento) não expressaram opinião sobre o tema. A clareza na comunicação entre gestores e colaboradores deve ser uma norma a ser seguida dentro de toda organização.

UFAMBR, Manaus, v. 3, n. 1, art. 4, pp. 54-78, janeiro-junho, 2021 http://www.periodicos.ufam.edu.br/ufambr 
Clima organizacional: Um estudo de caso com Auditores Técnicos de Controle Externo do Tribunal de Contas do Estado do Amazonas (TCE/AM)

Os colaboradores devem estar bem informados, se comunicando de maneira adequada. Para que se possa alinhar os objetivos da empresa aos das pessoas que são responsáveis pelo sucesso organizacional (Tibúrcio \& Santana, 2014).

Em seguida, 64\% (sessenta e quatro por cento) dos servidores encontram as informações na Intranet; $32 \%$ (trinta e dois por cento) escolheram a opção colega de trabalho e somente 4\% (quatro por cento) encontram as informações com o chefe. Toda empresa ou órgão público é formada por diversos funcionários que necessitam trabalhar com uma comunicação integrada para que possam alcançar as metas e os objetivos. Com isso, os canais de comunicação da organização se tornam valiosos, visto que tem como propósitos: informar, alinhar o clima e a cultura organizacional.

Em relação à variável "Treinamento" (Tabela 8), avalia-se as oportunidades que os trabalhadores têm de se qualificarem e se consideram suficientes para a realização do trabalho (Luz, 2003).

Tabela 8

Variável Treinamento

\begin{tabular}{lcc}
\hline 17. Você considera suficiente o treinamento dado pelo TCE/AM? & Respondentes & \% \\
\hline Sim & 7 & $28 \%$ \\
Não & 18 & $72 \%$ \\
Não tenho opinião. & 0 & $0 \%$ \\
\hline 18. O treinamento que você recebe o capacita a fazer bem o seu & Respondentes & $\%$ \\
trabalho? & 0 & $0 \%$ \\
\hline Sempre & 11 & $44 \%$ \\
Quase sempre & 14 & $56 \%$ \\
Raramente & 0 & $0 \%$ \\
Nunca & 0 & $0 \%$ \\
Não tenho opinião & & \\
\hline
\end{tabular}

Fonte: Dados da pesquisa, 2019.

Os dados da décima sétima questão é insatisfatória, uma vez que $72 \%$ (setenta e dois por cento) dos pesquisados manifestaram que consideram insuficiente o treinamento proporcionado pelo TCE/AM; e somente $28 \%$ (vinte e oito por cento) encontram-se satisfeitos com o treinamento/desenvolvimento. A Corte de Contas deve ficar atenta a esta variável, visto que os treinamentos motivam, valorizam e melhoram as habilidades dos servidores. De acordo com Triguero e Peña (2018), o treinamento como uma das ferramentas da gestão de recursos humanos é responsável pelo desempenho dos funcionários e o desenvolvimento organizacional.

Percebe-se no em seguida que somente $44 \%$ (quarenta e quatro por cento) acredita que o treinamento oferecido capacita para a realização de um bom trabalho, enquanto os insatisfeitos é maior, pois 56\% (cinquenta e seis por cento) afirmam que raramente o treinamento atende às necessidades para a realização do trabalho. Todo treinamento oferecido pela organização deve ser suficiente para a realização do trabalho, pois Marques (2016, p. 87) explica que "o treinamento se apresenta como um instrumento fundamental para aumentar a produtividade no trabalho, fonte de satisfação e motivação para o empregado". Conforme Fidelis $(2014$, p. 84$)$ "o treinamento significa aumentar a capacidade das pessoas para produzir, aperfeiçoando a sua forma de entendimento e participando mais do ambiente no qual interagem". 
Clima organizacional: Um estudo de caso com Auditores Técnicos de Controle Externo do Tribunal de Contas do Estado do Amazonas (TCE/AM)

O treinamento tem como objetivo direcionar os servidores do órgão, capacitando para eventuais atividades ou serviços no setor de trabalho (Pereira, Aragão \& Gomes, 2015).

A variável seguinte analisada foi o "Reconhecimento" (Tabela 9) que avalia o quanto a organização adota mecanismos de valorização e reconhecimento para seus funcionários (Luz, 2003).

Tabela 9

\section{Variável Reconhecimento}

\begin{tabular}{lcc}
\hline $\begin{array}{l}\text { 19. Você recebe o reconhecimento devido quando realiza um } \\
\text { bom trabalho? }\end{array}$ & Respondentes & \% \\
\hline Sempre & 5 & $20 \%$ \\
Quase sempre & 13 & $52 \%$ \\
Raramente & 6 & $24 \%$ \\
Nunca & 1 & $4 \%$ \\
Não tenho opinião & 0 & $0 \%$ \\
\hline 20. Você considera que seu potencial de realização profissional & Respondentes & $\%$ \\
tem sido adequadamente aproveitado? & 3 & $12 \%$ \\
\hline Sempre & 8 & $32 \%$ \\
Quase sempre & 12 & $48 \%$ \\
Raramente & 0 & $0 \%$ \\
Nunca & 2 & $8 \%$ \\
Não tenho opinião & & \\
\hline
\end{tabular}

Nota: Dados da pesquisa, 2019.

Conforme os dados da décima nona pergunta, cerca de $72 \%$ (setenta e dois por cento) dos servidores recebem o reconhecimento devido quando realizam um bom trabalho, e $28 \%$ (vinte e oito por cento) dizem não receber reconhecimento. $\mathrm{O}$ gestor tem a responsabilidade de demonstrar o reconhecimento profissional a cada colaborador, porque é ele quem observa as capacidades dos funcionários e tem condições de fazer elogios ao trabalho realizado. Por essa razão, a autoestima, respeito e reconhecimento estão diretamente ligados ao desempenho e produtividade. Logo, é importante que as organizações valorizem esta variável, pois do contrário será difícil cobrar resultados dos colaboradores.

De acordo com Marques (2016), existem diversas alternativas que proporcionam a motivação no trabalhador, em destaque o reconhecimento profissional, visto que contribui de maneira positiva à produtividade e ao clima organizacional.

A vigésima questão, a insatisfação se encontra maior, visto que $48 \%$ (quarenta e oito por cento) dos servidores indicaram que seu potencial não tem sido adequadamente aproveitado; e $44 \%$ (quarenta e quatro por cento) afirmam o contrário. O superior do setor deve estar atento ao desempenho dos funcionários e saber identificar talentos para que a equipe não só consiga bons resultados, mas também motive o colaborador, já que ele saberá que seu potencial está sendo levado em consideração. Para isso, a utilização da gestão de competência pelos líderes pode alinhar as habilidades profissionais com as estratégias da organização, metas e objetivos. Outra ferramenta que pode ser utilizada é avaliação de desempenho que busca estimular às qualidades do funcionário, incentivando o potencial de desenvolvimento futuro. Segundo Chiavenato (2004), a avaliação de desempenho possui caráter orientativo, visto que traça novos rumos aos desvios e incentiva os pontos fortes de cada colaborador. 
Clima organizacional: Um estudo de caso com Auditores Técnicos de Controle Externo do Tribunal de Contas do Estado do Amazonas (TCE/AM)

\subsection{Análise da Percepção dos Auditores Técnicos de Controle Externo sobre a Influência do Clima Organizacional na Produtividade}

Nessa fase do estudo, procurou-se entender a percepção dos servidores da Diretoria de Controle Externo de Obras Públicas sobre a influência do clima organizacional na produtividade. A tabela 10 apresentará os dados.

Tabela 10

Influência do Clima Organizacional na Produtividade

\begin{tabular}{lcc}
\hline $\begin{array}{l}\text { 21. Em sua opinião, o Clima Organizacional da DICOP exerce } \\
\text { influência sobre a produtividade? }\end{array}$ & Respondentes & $\%$ \\
\hline Sim & 19 & $76 \%$ \\
Não & 3 & $12 \%$ \\
Mais ou menos. & 3 & $12 \%$ \\
\hline 22. A produtividade da sua equipe afeta sua motivação? & Respondentes & \% \\
\hline Afeta muito & 12 & $48 \%$ \\
Afeta pouco & 7 & $28 \%$ \\
Não afeta & 5 & $20 \%$ \\
Não tenho opinião & 1 & $4 \%$ \\
\hline
\end{tabular}

Fonte: Dados da pesquisa, 2019.

Na vigésima primeira questão, $76 \%$ (setenta e seis por cento) acreditam que o clima influencia sim na produtividade e somente $12 \%$ (doze por cento) dizem que não há influência na produtividade. Com base nos resultados apresentados, é possível afirmar que criar um ambiente de trabalho motivador e que atenda às necessidades dos funcionários, tem como resultado o aumento da produtividade e a qualidade no serviço. Segundo Luz (2003), a estratégia para se avaliar o ambiente interno da empresa ou órgão público é a pesquisa de clima organizacional, uma vez que fornece informações para identificar variáveis organizacionais que precisam ser melhoradas e possibilita que a organização realize mudanças no ambiente, buscando melhoria no desempenho de seus colaboradores. Segundo Barçante e Castro (1999), alcançar serviços de qualidade depende do clima organizacional, ao passo que, aumentando a satisfação no trabalho, tende-se a conseguir resultados melhores de produtividade.

Em seguida, $48 \%$ (quarenta e oito por cento) afirmam que a produtividade da equipe a afeta muito a motivação individual; $48 \%$ (quarenta e oito por cento) dizem que não afeta; e 4\% (quatro por cento) não manifestaram opinião. Esses dados demonstram que o gestor deve ficar atento a produtividade da equipe, visto que tanto os setores, como servidores possuem metas que devem ser cumpridas. Quando não atingem a meta em grupo, aumenta a frustração com aqueles que não estão completamente envolvidos com os objetivos e metas do setor de trabalho

\section{CONCLUSÃO}

A pesquisa aqui exposta teve como objetivo analisar a influência que o clima organizacional exerce sobre a produtividade dos servidores da Diretoria de Controle Externo de Obras Públicas do TCE/AM. Por meio da avaliação de 8 (oito) variáveis organizacionais, foi proposta a avaliação do clima organizacional da diretoria para apresentar melhorias, caso necessário, contribuindo no aumento e qualidade da produtividade do órgão de acordo com os dados colhidos na DICOP.

UFAMBR, Manaus, v. 3, n. 1, art. 4, pp. 54-78, janeiro-junho, 2021 http://www.periodicos.ufam.edu.br/ufambr 
Clima organizacional: Um estudo de caso com Auditores Técnicos de Controle Externo do Tribunal de Contas do Estado do Amazonas (TCE/AM)

Os servidores da Diretoria de Controle Externo de Obras Públicas possuem de 5 a 10 anos de trabalho no órgão, com idade predominante entre 30 a 40 anos e todos os respondentes do estudo são do sexo masculino, pois não foram obtidas respostas do sexo feminino. Isso mostra que o órgão precisa de uma renovação no quadro de funcionários da Diretoria para a manutenção dos processos organizacionais, visto que em breve estarão na idade de se aposentarem comprometendo a força de trabalho da organização, e a necessidade de se equilibrar a distribuição de gênero no setor para um maior aproveitamento da produtividade.

As condições de trabalho identificadas na pesquisa foram satisfatórias para o clima da Diretoria. Presume-se que os resultados de insatisfação quanto a ruídos, temperatura e outros sejam por conta da reforma que estava ocorrendo no órgão no momento da realização dessa pesquisa. Apesar disso, é notável o esforço da Corte de Contas em melhorar as condições físicas do local de trabalho. Outrossim, os recursos tecnológicos colocados à disposição dos servidores foram considerados pela maioria dos respondentes como satisfatório para a realização do trabalho. Dessa forma, todas as organizações devem procurar ter um ambiente saudável. Para isso, é preciso ter tanto o ambiente físico satisfatório (iluminação, temperatura e ruídos), quanto também aspectos psicológicos (sentimento de segurança e conforto) para diminuir ou prevenir a insegurança.

Quanto ao comprometimento dos servidores, os resultados da pesquisa demonstram que eles se encontram comprometidos com o trabalho no setor. Porém, existe um sentimento de não pertencimento quanto aos objetivos organizacionais, pois somente $48 \%$ encontram-se comprometidos com as metas do TCE/AM. Para que o programa "Estoque Zero" atinja seus objetivos é imperativo que os colaboradores estejam envolvidos e se importem com as estratégias do órgão. Além disso, deve ser verificado se as mensagens dirigidas aos servidores estão sendo compreendidas a fim de conscientização das metas.

Em relação à variável "Trabalho Realizado pelos Funcionários", a pesquisa indicou que corre a sobrecarga de alguns servidores da Diretoria, pois o volume de trabalho é considerado elevado. Além disso, merece destaque o resultado do questionamento sobre o trabalho em equipe, no qual somente $28 \%$ dos servidores afirmam perceber o trabalho sendo realizado em conjunto. Apesar disso, notou-se que os servidores se sentem satisfeitos com as decisões tomadas pelos superiores que podem afetar seus trabalhos e valorizam mais a qualidade no lugar da quantidade.

O estudo identificou também alguns outros fatores positivos, na variável "Liderança", entre a chefia e o colaborador existe uma relação harmoniosa, pois não existe uma pressão excessiva sobre o trabalho realizado e consideram que seus trabalhos são avaliados de maneira justa. Na variável "Comunicação", 80\% dos servidores considera ter uma ideia clara do resultado esperado. Outra variável satisfatória foi "Reconhecimento", na qual $72 \%$ dos respondentes afirmam receber um reconhecimento devido quando realizam um bom trabalho.

É preciso atenção à variável "Remuneração", visto que a maioria dos servidores se encontram insatisfeitos com os salários. Por se tratar de órgão público, devem-se levar em consideração os reajustes salariais e a compatibilidade dos salários quando comparado com as outras Cortes de Contas Estaduais. É interessante que apesar de a remuneração não ser o principal fator que gera motivação, é um fator que mais pode produzir insatisfação no trabalho.

UFAMBR, Manaus, v. 3, n. 1, art. 4, pp. 54-78, janeiro-junho, 2021 http://www.periodicos.ufam.edu.br/ufambr 
Outra variável investigada nesse estudo diz respeito às ações de desenvolvimento e treinamento oferecidos e que foram consideradas insuficientes, pois, na percepção dos respondentes, raramente ocorrem oportunidades de crescimento profissional. 56\% dos servidores afirmaram ainda que os treinamentos oferecidos não alcançam as necessidades imediatas do trabalho.

Outro dado fundamental obtido com a pesquisa é que $48 \%$ responderam que a produtividade do grupo de trabalho afeta a sua motivação individual. Portanto, é essencial uma preocupação maior com a produtividade da equipe, fazendo-se uma avaliação a fim de evitar a desmotivação individual e consequentemente índices desagradáveis de produtividade no setor.

Conclui-se, a partir dos dados da pesquisa, em que o clima organizacional da DICOP influencia fortemente a produtividade da Diretoria. Logo, trabalhando-se as variáveis pesquisadas que se encontram com altos índices de insatisfação, será possível o aumento da produtividade. Considerando que o clima tem forte influência na produtividade, a desatenção a esse fator pode causar um clima insatisfatório e consequentemente ocasionar baixos índices de produtividade. $\mathrm{O}$ fato pode estar ocorrendo em outras Diretorias e Departamentos do Tribunal de Contas do Estado do Amazonas, o que leva à necessidade de um estudo mais amplo em outros setores.

As limitações deste estudo se deram, primeiro, pelo fato da utilização de questionário para a coleta de dados, pois apesar da praticidade na aplicação, o questionário não permite captar sentimentos que são de caráter subjetivo. Assim, uma pesquisa com abordagem qualitativa poderia resolver essa limitação para obter uma interpretação melhor dos resultados desta pesquisa. Pode ser considerada outra limitação desse estudo o fato de terem sido abordados apenas os servidores concursados do órgão, deixando de fora os estagiários e servidores comissionados. Ainda assim, esta pesquisa oferece resultados consistentes para outros estudos que buscam analisar o clima organizacional e a produtividade no setor público.

Para estudos futuros, recomenda-se a utilização não só de outros modelos de autores sobre clima organizacional, mas também outras variáveis organizacionais e que seja realizada investigação completa em todos os setores do órgão para confirmar se os resultados encontrados na Diretoria podem ocorrer no órgão como um todo. Torna-se mister uma análise das variáveis negativas para solucionar e proporcionar o pleno alinhamento dos objetivos organizacionais com os objetivos dos servidores de forma a não prejudicar a produtividade da organização.

\section{REFERÊNCIAS}

Affonso, L. M. F. \& Rocha, H. M. (2010). Fatores organizacionais que geram insatisfação no servidor público e comprometem a qualidade dos serviços prestados. VII SEGET - Simpósio de Excelência em Gestão e Tecnologia, v. 7.

UFAMBR, Manaus, v. 3, n. 1, art. 4, pp. 54-78, janeiro-junho, 2021 http://www.periodicos.ufam.edu.br/ufambr 
Clima organizacional: Um estudo de caso com Auditores Técnicos de Controle Externo do Tribunal de Contas do Estado do Amazonas (TCE/AM)

Araújo, C. C. S. et al. (2017) Análise da Relação entre Clima Organizacional e o Desempenho Criativo em Organizações Brasileiras. NAVUS - Revista de Gestão e Tecnologia, v. 7, n. 2, pp. 97-112.

Araújo, M. (2017). Como realizar uma avaliação de desempenho justa e eficaz? Recuperado de: $<$ https://administradores.com.br/artigos/como-realizar-uma-avaliacao-de-desempenho-justae-eficaz>.

Belluno. A. (2020). Gestão participativa: a importância de ouvir os funcionários. Recuperado de:<https://www.bellunotec.com.br/blog/gestao-participativa-a-importancia-de-aprender-aouviros-funcionarios/>.

Bortolozo, A. \& Santana, D. (2011). Qualidade de vida no trabalho: os fatores que melhoram a qualidade de vida no trabalho. Recuperado de: <http://www.unifil.br/portal/arquivos/publicacoes/>.

Barçante, L. C. \& Castro, G. C. (1999). Ouvindo a voz do cliente interno: transforme seu funcionário. Rio de Janeiro: Qualitymark.

Beuren, I. M., Kaveski, I. D. S., \& Rigo, V. P. (2014). Associação das medidas de desempenho para pagamento de bônus aos executivos com dependência de capital humano. Revista Contemporânea de Contabilidade, 11(22).

Bugarin, M. \& Meneguin, F. B. (2016). Incentivos à corrupção e à inação no serviço público: Uma análise de desenho de mecanismos. Estud. Econ., São Paulo, v. 46, n. 1, pp.43-89, mar. Recuperadode:<http://www.scielo.br/scielo.php?script=sci_arttext\&pid=S010141612016000 $100043 \& \operatorname{lng}=$ en $\&$ nrm=iso $>$.

Chiavenato, A. (2004). Gestão de Pessoas: e o novo papel dos recursos humanos nas organizações. 6. ed. Rio de Janeiro: Elsevier.

Carbone, P. P. (2000). Cultura organizacional no setor público brasileiro: desenvolvendo uma metodologia de gerenciamento da cultura. Revista de Administração Pública, Rio de Janeiro, v. 34, n. 2, p. 133-144.

Dias, J. M. A. M., \& Borges, R. S. G. (2015). Estilos de liderança e desempenho de equipes no setor público. REAd-Revista Eletrônica de Administração, 21.

Diehl, A. A., \& Tatim, D. C. (2004). Pesquisa em ciências sociais aplicadas: Métodos e Técnicas. Prentice Hal.

Ferreira, A. et al. (2006). Teorias de motivação: uma análise da percepção das lideranças sobre suas preferências e possibilidade de complementaridade. XIII SIMPEP UNESP, pp. 1 - 12.

Fidelis, G. J. (2014). Gestão de Pessoas: Estrutura, processos e estratégias empresariais. São Paulo: Érica.

Filho, G. I. R. \& Ribeiro, D., M. (2012) Gestão do Clima Organizacional - Conceitos, diagnostico e estratégia gerenciais. In: XXXII Encontro Nacional de Engenharia de Produção, XXXII. 2012, Bento Gonçalves. Anais...Rio Grande do Sul: p. 01-13.

Filho, F. M., \& Arruda, F. E. J. (2013). Planejamento da Pesquisa Cientifica. São Paulo: Atlas.

Gil, A. C. (2008). Métodos e Técnicas de pesquisa socia. São Paulo: Atlas, p. 156.

Gonçalves, J. (2016) Clima organizacional e turismo: um estudo de pesquisas em organizações de turismo. X Fórum Internacional De Turismo Do Iguaçu, 2016, Foz do Iguaçu - Paraná. Tema: Clima organizacional e turismo.

Lacava, A. (2018). Como a pressão do chefe pode ser uma aliada na carreira. Recuperado de: $<$ https://administradores.com.br/noticias/como-a-pressao-do-chefe-pode-ser-uma-aliada-nacarreira>.

Lacombe, F. J. (2012). Recursos humanos: princípios e tendências. São Paulo: Saraiva.

UFAMBR, Manaus, v. 3, n. 1, art. 4, pp. 54-78, janeiro-junho, 2021 http://www.periodicos.ufam.edu.br/ufambr 
Clima organizacional: Um estudo de caso com Auditores Técnicos de Controle Externo do Tribunal de Contas do Estado do Amazonas (TCE/AM)

Lima, L. C., Leuch, V., \& Buss, B. R. (2017). A importância da pesquisa de clima organizacional para análise do nível de satisfação dos colaboradores e da estrutura organizacional. Espacios, pp. v. 38, n. 28, p.13-22, abr. 2017.

Ludke, M. \& André, M. (2013). Pesquisa em educação: abordagens qualitativas. Rio de Janeiro: E.P.U.

Luz, R. (2003). Gestão do clima organizacional. Rio de Janeiro: Qualitymark

Luz, S. M. (2006). Qualidade de vida: estudo descritivo, quantitativo, observacional da qualidade de vida de profissionais da área de informática. 78 f. Monografia (Especialização em Gerenciamento de Banco de Dados) - Universidade do Extremo Sul Catarinense, Criciúma.

Machado, R. Z., \& Goulart, M. M. (2014). A pesquisa de clima e sua importância como ferramenta estratégica de gestão para as organizações: um estudo comparativo no ramo da engenharia consultiva. Congresso nacional de excelência em gestão (pp. 2014. p. 1 - 18). Rio de Janeiro: Fieb.

Mallet, R. (2009). Os Inimigos do Clima Produtivo. Recuperado de:< http://www.administradores.com.br/artigos/economia-e-financas/clima-organizacional-opoder-do-ambiente-sobre-a-produtividade/31314>.

Marques, J. C. (2016). Gestão de recursos humanos (recurso eletrônico). São Paulo: cengage.

Marques, J. R. (2016). O reconhecimento profissional como fator motivacional no trabalho. Recuperado de: <https://www.jrmcoaching.com.br/blog/o-reconhecimento-profissionalcomo-fator-motivacional-no-trabalho/ $>$.

Maximiano, A. C. (2009). Teoria Geral da Administração: da revolução. São Paulo: Atlas.

Maximiano, A. C. (2015). Introdução à teoria geral da administração. São Paulo: Atlas

Medeiros, R. (2006). A Comunicação Interna numa Organização Pública. (Dissertação). Universidade Federal do Rio Grande do Norte, Natal, Brasil. Recuperado de: <ftp://ftp.ufrn.br/pub/biblioteca/ext/bdtd/RildeniroM.pdf>.

Mendonça, B. (2018). Como potencializar o trabalho em equipe na sua empresa? Recuperado de: <https://www.edools.com/trabalho-em-equipe/>.

Michel, M. H. (2015). Metodologia e pesquisa científica em ciências sociais: um guia prático para acompanhamento da disciplina e elaboração de trabalhos monoFiguras. (3a ed.), São Paulo: Atlas.

Ministério da Fazenda (2016). Governo divulga boletins de análise dos gastos federais edas finanças públicas estaduais. Recuperado de:<http://www.fazenda.gov.br/noticias/2016/maio/200brelatorio-de-analise-dos-gastospublicos-federais-revela-rigidez-orcamentaria-e-peso-da-previdencia $>$.

Nascimento, F. P., \& Souza, F. L. (2015). Metodologia da pesquisa científica: teoria e prática: como elaborar TCC. Fortaleza: INESP.

Nittis, L. (2018). Setor público: iniciativas para gerar mais produtividade no trabalho. Recuperado de: <https://www.e-gestaopublica.com.br/setor-publico-mais-produtividade-notrabalho/>.

Nursalam, N., Elina, Y., \& Wahyuni, E. D. (2017). The analysis of job satisfaction nurse based on organizational climate. Jornal Ners, pp. 154-163.

Oliveira, D. d., Carvalho, R. J., \& Rosa, A. C. (2012). Clima Organizacional: Fator de Satisfação no Trabalho e Resultados Eficazes na Organização. 14 simpósio de excelência em gestão e tecnologia.

UFAMBR, Manaus, v. 3, n. 1, art. 4, pp. 54-78, janeiro-junho, 2021 http://www.periodicos.ufam.edu.br/ufambr 
Clima organizacional: Um estudo de caso com Auditores Técnicos de Controle Externo do Tribunal de Contas do Estado do Amazonas (TCE/AM)

Oliveira, J. C., Oliveira, A. L., Morais, F. d., Silva, G. M., \& Silva, C. N. (2016). O questionário, o formulário e a entrevista como instrumento de coleta de dados. Congresso nacional de educação - CONEDU, 8.

Oliveira, J. A. de \& Medeiros, M. P. M. (2011). Gestão de pessoas no setor público. Florianópolis: Departamento de ciências da Administração/UFSC.

Pereira, M., Aragão, J., \& Gomes, R. (2015). A importância do treinamento e capacitação de pessoas: um estudo de caso na lavanderia industrial alfa. Recuperado de: <http://www.rhportal.com.br/artigos/rh.php?rh=-A-Importancia-Do-Treinamento-

Eapacitacao-De-Pessoas:--Um-Estudo-De-Caso-Na-Lavanderia-Industrial$\% 20 \& i d c \_c a d=$ sslq6jxoo $>$.

Pérez, A. M. (2017). Comunicación organizacional como dimensión necesaria para medir el clima en las organizaciones en salud pública. Revista Cubana de Salud Pública, v. 16, n. 1, p.57-67.

Pública, J. (2018). Entenda como aperfeiçoar a Gestão no Setor Público. Recuperado de: $<$ https://jpfgv.com.br/entenda-como-aperfeicoar-a-gestao-de-pessoas-no-setor-publico/>.

Rocha, A. C.; Ceretta, G. F. \& Lima, J. (2014). Clima organizacional em hospital: um estudo no Sudoeste do Paraná. Reuna, v. 19, n. 2, pp. 71-90, 2014.

Sampieri, R, H., Collado, C, F. \& Lucio, P. B. (2006). Metodologia de Pesquisa. 3. Ed. Trad.: Fátima Conceição Murad; Melissa Kassner; Sheila Clara Dystyler Ladeira. São Paulo: McGraw-Hill Interamericana do Brasil Ltda.

Santos, L. J., \& Paranhos, M. S. (2017). Os trabalhadores das Equipes de Saúde da Família no Rio de Janeiro: aspectos da liderança em pesquisa de clima organizacional. Ciência \& Saúde Coletiva, vol.22, n.3, p.759-770. ISSN 1413-8123. http://dx.doi.org/10.1590/141381232017223.33112016.

Santana, C. (2018). Excesso de trabalho: riscos para a saúde e diminuição de produtividade. Recuperado de: <https://blog.acsendo.com/pt/excesso-trabalho-riscos-saude-diminuicaoprodutividade/>.

SEBRAE. (2017). Clima Organizacional: A importância de um bom clima organizacional na empresa. Recuperado de: <http://www.sebrae.com.br/sites/PortalSebrae/bis/a-importanciado-bom-clima-organizacional-na empresa,73fe9bda15617410VgnVCM2000003c74010aRCRD>.

Spector, P. E. (2010). Psicologia nas organizações. (3a. ed.), São Paulo: Saraiva.

Staudt, D. \& Reggiori, G., M. (2016). O Real Significado da Motivação. Revista Gestão e Conhecimento.

Saraiva, L. A. S. (2002). Cultura organizacional em ambiente burocrático. RAC: Revista de Administração Contemporânea, Maringá, v. 6, n. 1, p. 187-207.

Taniguchi, K., \& Costa, A. L. (2010). Clima organizacional: Uma ferramenta estratégica para o diagnóstico em recursos humanos. Revista de Ciências Gerenciais, p.207-223.

Tenório, F. G. (1998). Gestão social: uma perspectiva conceitual. Recuperado de: <http://bibliotecadigital.fgv.br/ojs/index.php/rap/article/viewFile/7754/6346>.

Tibúrcio, S. J., \& Santana, L. C. (2014). A comunicação interna como estratégia organizacional. Revista de Iniciação Científica Cairu.

Triguero, S. R. \& Peña, V. J. (2018). Como Melhorar o Desempenho da Empresa por Meio da Diversidade de Colaboradores e da Cultura Organizacional. Revista Brasileira de Gestão de Negócios, v. 20, n. 3, p. 378-400. 
Clima organizacional: Um estudo de caso com Auditores Técnicos de Controle Externo do Tribunal de Contas do Estado do Amazonas (TCE/AM)

UFAMBR, Manaus, v. 3, n. 1, art. 4, pp. 54-78, janeiro-junho, 2021 http://www.periodicos.ufam.edu.br/ufambr 